\title{
Entre máscaras e espelhos: reflexões sobre a Identidade e o ensino de História da África nas escolas brasileiras ${ }^{1}$
}

\author{
Among masks and mirrors: reflections about Identity \\ and the teaching of African history in Brazilian schools
}

Anderson Ribeiro Oliva*

\section{RESUMO}

O presente artigo tem como objetivo analisar os reflexos, na construção das identidades individuais e coletivas de estudantes, das abordagens de conteúdos sobre a história africana no ensino brasileiro. Partindo dos referenciais teóricos ligados aos Estudos Culturais, o trabalho analisa a forma como o tratamento concedido ao assunto pode fomentar, interditar e justificar a existência de reflexos identitários plurais - com a presença das 'máscaras' africanas de reconhecimento do outro e de autorreconhecimento - em nossos espaços escolares. Ao mesmo tempo o texto se propõe a discutir o sentido da identidade nacional em uma sociedade composta por conjuntos populacionais híbridos, complexos e marcados pelas relações interculturais e multiculturais geradas ao longo de sua composição histórica mais recente.

Palavras-chave: identidades; ensino de história africana; Estudos Culturais.

\begin{abstract}
This article aims at analyze the reflexes, in the construction of individual and collective identities of students, of the approaches of contents about African history in Brazilian education. Based on the theoretical references connected to Cultural Studies, the study analyzes how the treatment accorded to the subject can foster, interdict and justify the existence of plural reflections of identity with the presence of the African 'masks' of recognition of others and of self-recognition - in our school spaces. The text also proposes to discuss the meaning of national identity in a society composed by hybrid sets of population, complex and marked by intercultural and multicultural relations formulated along its recent historical composition.

Keywords: identities; teaching of African history; Cultural Studies.
\end{abstract}

${ }^{*}$ Departamento de História, Instituto de Ciências Humanas, Universidade de Brasília (UnB). Campus Universitário Darcy Ribeiro, ICC Ala Norte, 1º andar, s645/62 Asa Norte. 70190-900 Brasília - DF - Brasil. oliva@unb.br 
No Brasil, um dos debates mais frutíferos sobre a questão da Identidade Nacional foi vivenciado nos últimos dez anos. Motivado, entre outros ingredientes, pela implementação das cotas raciais em algumas universidades públicas brasileiras, é certo afirmar que um dos seus efeitos positivos foi forçar uma parte significativa da sociedade brasileira, até então desinteressada em relação ao tema, a se posicionar ou a refletir sobre os mitos fundadores da identidade nacional, sobre as nossas múltiplas identidades e as distorções experimentadas nas relações interidentitárias.

Observamos, na realidade, o continuar das experiências de fabricação da Identidade Nacional, talvez tão impactantes quanto aquelas iniciadas na segunda metade do século XIX (caracterizadas pela negação da pluralidade étnica, pela valorização de nossa suposta eurodescendência e pelos referenciais teóricos do Determinismo Racial) e na década de 1930 (com a defesa de uma suposta cultura nacional homogeneizadora e embebida na ideia da miscigenação e da 'democracia racial').

$\mathrm{O}$ atual momento, iniciado há pelo menos quarenta anos, refunda algumas de nossas velhas crenças redefinindo a Identidade Nacional a partir da combinação ou coexistência de outras identidades. Esse 'novo' diálogo, envolvendo máscaras e reflexos identitários, que é muito mais revelador para os teóricos/educadores, e muito mais significativo para aqueles que se veem forçados a assumir ou a negar o pertencimento a alguma dessas 'outras identidades', parece ser mais funcional e crível do que o suposto manto de uma identidade comum que recobriria a todos.

A cultura e a identidade nacionais (ditas no singular) foram substituídas, neste caso, por um conjunto multifacetado e plural de práticas, ideias, padrões de comportamento, características psicológicas, estéticas, definições sobre identidade e alteridade que criam um mosaico de percepções de pertencimento e de estranhamento que abalaram fundações que pareciam indestrutíveis. Não somos apenas 'brasileiros'. Somos afro-brasileiros, nipo-brasileiros, luso-brasileiros, teuto-brasileiros, ítalo-brasileiros. Mais do que isso, somos também homens e mulheres; nordestinos ou nortistas; brancos e negros; moradores de bairros diferentes; exercemos profissões distintas (inclusive no status); somos portadores de crenças e estilos distintos. É claro que essas múltiplas identidades sempre nos pertenceram, mas elas ficavam esquecidas quando as 
relações interidentitárias nos forçavam a uma definição homogênea ou exclusiva: ser brasileiro.

Não me parece absurdo lembrar que o debate acerca das identidades multiculturais e das relações interculturais não é uma exclusividade do cenário brasileiro. Outros espaços globais têm sido tocados cotidianamente pela questão. Nas Américas, na África e na Europa (para limitarmos nossos olhares aos efeitos das diásporas africanas mais recentes), a situação dos imigrantes africanos e das crescentes parcelas das populações de alguns países formadas por seus descendentes intensifica o debate sobre as identidades a cada caso de racismo, xenofobia, ou de explosões sociais vindas das periferias. Motivados por esses contextos complexos, há alguns anos, vários teóricos têm se dedicado ao estudo dessas realidades. Dentre esses, um grupo tem chamado a atenção pelo seu formato híbrido: são teóricos/cientistas, mas são também integrantes de experiências diaspóricas ou pós-coloniais, que procuram explicar, entender e vivenciar. Acredito que nenhum outro conjunto de especialistas avançou tanto sobre esse debate como aqueles vinculados aos "Estudos Culturais" (Cultural Studies) ou aos Estudos Pós-Coloniais. ${ }^{2}$

Entre os debates intentados por esses teóricos, a fundação e o emprego de algumas categorias/conceitos, como multiculturalismo, culturas híbridas e identidades plurais, resultaram como potenciais ferramentas de análise e compreensão de várias experiências histórico-culturais ocorridas em sociedades cunhadas pelas diásporas e pelas migrações, recentes ou não. Neste caso, me parece certo que, para refletirmos com nossos estudantes sobre a relevância de conteúdos vinculados à história africana em seus cotidianos escolares existe um obrigatório eixo ou elemento de articulação: o debate reflexivo sobre as identidades.

Fundamentalmente, é sobre isso que estamos a falar. Como nos identificamos? Como identificamos aos Outros? Sejam eles, ou sejamos nós, o que formos, falamos sobre os critérios de descrição, atribuição, reconhecimento ou negação de uma ou várias identidades. As relações identitárias, o multiculturalismo e os mecanismos relacionais devem tencionar a Escola a assumir uma nova postura perante a pluralidade cultural e as identidades plurais brasileiras.

Partindo do cenário descrito, o presente artigo tem como objetivo maior refletir acerca dos possíveis reflexos, na construção das identidades individuais e coletivas de estudantes, das abordagens de conteúdos da história africana no ensino brasileiro. A intenção principal do trabalho é analisar a forma como o 
tratamento concedido ao assunto pode fomentar, interditar e justificar a existência de reflexos identitários multiculturais - com a presença das 'máscaras' africanas de reconhecimento do outro e de autorreconhecimento - em nossos espaços escolares. Ao mesmo tempo o texto se propõe a discutir o sentido da identidade nacional em uma sociedade composta por conjuntos populacionais híbridos e complexos em meio às relações interculturais e multiculturais geradas ao longo de sua composição histórica mais recente.

\section{ENTRE MÁSCARAS IDENTITÁRIAS E ESPELHOS. O DEBATE SOBRE} AS IDENTIDADES E O ENSINO DE HISTÓRIA AFRICANA

Um dos objetivos principais da Educação Básica brasileira sinaliza para a necessidade de que estudantes e professores devam reconhecer e valorizar a "pluralidade do patrimônio sociocultural brasileiro", e, ao mesmo tempo, conhecer também os "aspectos socioculturais de outros povos ... posicionando-se contra qualquer discriminação". ${ }^{3}$ Neste caso, a própria Lei de Diretrizes e Bases da Educação Nacional (9.394/1996), já determinava, em 1996, que a abordagem da história do Brasil nas escolas deveria "levar em conta as contribuições das diferentes culturas e etnias para a formação do povo brasileiro", entendidas nos termos empregados pela lei como as "matrizes indígena, africana e europeia". ${ }^{4}$ Esses elementos foram sintetizados em um dos pressupostos centrais para o ensino brasileiro pelos Parâmetros Curriculares Nacionais (PCNs), com base em um de seus temas transversais: a Pluralidade Cultural.

Dessa forma os textos dos PCNs já incorporavam, no final da década de 1990, as mudanças teóricas de definição das identidades que circulavam nos meios acadêmicos e movimentos sociais há algumas décadas, criticando abertamente a percepção de que a Identidade Nacional seria entendida com base na adesão a um conjunto comum de valores culturais por um grupo homogêneo de pessoas. Pluralidade cultural, diversidade étnica, identidades plurais e trajetórias históricas distintas passaram a ser tratadas como formadores daquilo que se entendia por 'povo brasileiro'. Ou seja, dissolvia-se a ideia de que existia 'um povo brasileiro', revelando-se que uma única Identidade Nacional só existia quando construíamos e compartilhávamos uma falsa imagem. No lugar dessa imagem deveria entrar outra: a do mosaico identitário, ou melhor, das Identidades Plurais e das Identidades Parciais. 
Nenhuma sociedade pode se pensar como homogênea ou como possuidora de uma única inscrição cultural/identitária. As diferenças das mais diversas ordens - de origem, social, gênero, profissão, cor, idioma, idade, região, escolaridade, território, religião - criam sulcos de formatos distintos dentro das sociedades e entre diferentes sociedades. Nossa 'brasilidade' apenas reflete-se no jogo de espelhos identitários quando provocada; quando, em determinadas épocas ou situações, somos forçados a revelar algumas de nossas máscaras de reconhecimento, defender ou negar o pertencimento a essa ou aquela inscrição. De outra forma, poderíamos voltar a perguntar o que forma ou o que define o pertencimento a esta identidade. O que é ser brasileiro?

Para alguns, tal resposta seria dada com base na descrição/inscrição de um elemento essencial ou na combinação de certos ingredientes: 'nasceu no Brasil' (território); 'fala português' (língua); 'é filho de brasileiros' (descendência sanguínea); 'é filho de pai ou mãe brasileiros' (descendência sanguínea parcial); 'sabe sambar, jogar futebol e gosta de carnaval' (ingredientes culturais); 'é cordial, simpático e tem o jeitinho brasileiro' (valores comportamentais). Se, em algumas situações, parece claro que somos 'brasileiros', em outras, parece ser fruto de um grande improviso nos classificarmos como iguais.

Estar diante do outro - estrangeiro (espanhol, estadunidense, japonês, mexicano, nigeriano) -, ser identificado pelo outro - quando na condição de imigrante ou em viagem ao exterior -, participar de certos momentos 'comuns' - eleições, competições esportivas -, talvez sinalizem para um pertencimento identitário também comum, mas obviamente pouco operacional e funcional apenas em poucas situações. Cotidianamente nos observamos e nos identificamos com base em outras inscrições, mais usuais e proximais do que a 'brasilidade'. Ou seja, nossa 'brasilidade' está carregada de sentidos, reflexos e máscaras distintas a partir do lugar identitário do qual falamos.

Não estamos afirmando com isso que não temos 'uma identidade nacional'. 'Ela' ou 'elas' existem. Inscrevemo-nos na 'brasilidade' ou a refletimos em algumas situações, como já afirmamos. Porém, mesmo nesses momentos, 'ela' ou 'elas' não nos igualam. Enfim, somos brasileiros (para aqueles que se consideram ou se inscrevem nesta identidade), mas possuímos outras inscrições identitárias, mais reveladoras, marcantes e coparticipantes em relação à primeira quando operamos as categorias de definição e identificação. Perceba-se, portanto, que não defendemos um revirar de faces ou identidades, apenas reforça- 
mos o argumento de que a definição 'brasileiro(a)' só pode ser entendida quando vista como um mosaico, composto por outras múltiplas faces, por diversas culturas, com a presença de maiorias e minorias. Identidades Plurais que se articulam, se atraem ou se rejeitam sob um 'guarda-chuva' identitário maior, a Identidade Nacional. Cada vez mais, para mais pessoas, faz mais sentido se pensar como nipo-brasileiro ou afro-brasileiro, do que como apenas 'brasileiro'.

Para descrever sociedades como a nossa, teóricos da cultura têm formulado definições ou categorias que procuram revelar e explicar os resultados dos encontros e desencontros de agentes, culturas e identidades plurais: culturas híbridas; sociedades Pluriculturais; sociedades Multiculturais e sociedades Interculturais, entre outras. No caso brasileiro, uma das definições mais frequentadas tem sido a do Multiculturalismo.

Neusa Maria Mendes de Gusmão esclarece que esse conceito pode ser entendido com base em duas componentes. A primeira refere-se a um 'fenômeno' vivenciado em muitas sociedades nas quais o pluralismo cultural se manifestou pelo encontro de vários agentes formadores, oriundos de espaços distintos e que se deslocaram em correntes migratórias pelos mais diversos motivos e tempos. A segunda confunde-se com uma série de políticas públicas contemporâneas - como na educação ou na formação profissional - com o objetivo de atender demandas de sociedades plurais. ${ }^{5}$ Seja como for, o emprego do termo é/foi marcado por algumas polêmicas e limitações. No entanto, entre outras 'equações teóricas' possíveis, ele representa uma forma de interpretar e, ao mesmo tempo, solucionar questões inerentes às sociedades marcadas profundamente pela diversidade de seus entes componentes.

O termo 'multiculturalismo' ganhou, no entanto, muitos críticos, entre outras razões, porque se limitaria "a constatar o estado das entidades sociais onde coabitam os grupos ou os indivíduos de culturas diferentes". Na mesma direção alguns autores afirmam que "multicultural é entendido como uma constatação da presença de diferentes culturas num determinado meio e da procura de compreensão das suas especificidades". O multiculturalismo coloca, sem sombra de dúvida, a heterogeneidade de formação de diferentes sociedades e torna evidente a questão das diferenças. As críticas decorrem do fato de que, na prática, todas as sociedades são multiculturais. (adaptado de Gusmão, 2004, p.61) 
Mesmo com suas limitações, ao ser manipulado por diversos sujeitos, o 'multiculturalismo' apresentou-se nas últimas décadas como uma forma de invenção social e de inscrição identitária. Ao mesmo tempo, revelou-se também como instrumento de intervenção pública, no esforço de certos agentes em (re)significar e modificar práticas que levaram/levam à construção de sociedades marcadas por profundas desigualdades e práticas discriminatórias.

Gusmão, ao analisar a situação vivenciada por jovens estudantes africanos ou luso-africanos (descendentes de imigrantes africanos) em escolas portuguesas nas décadas de 1980 e 1990, nos informa uma importante maneira de pensar as relações societárias, raciais e culturais em uma sociedade que se julgava monocultural, mas que na prática não o era.

A escola marcada pela multiplicidade étnico-cultural faz da educação um desafio como prática e como teoria, posto que envolve diferentes sujeitos, agentes, agências e instituições ... A chamada educação multicultural passa então a ser concebida na Europa e também em Portugal como condição de dar nota de uma realidade social formada por imigrantes e seus descendentes e, junto dela e em seu nome, reorientar as reivindicações que tais grupos elaboram perante os desmandos de uma ordem social injusta e excludente, perante os processos xenofóbicos e racistas do mundo europeu. O objetivo central é o de buscar uma sociedade baseada na igualdade e na tolerância. (Gusmão, 2004, p.63)

Portanto, ao partirmos do princípio de que somos membros de uma sociedade multicultural avançamos no esforço de identificar nossas várias ancestralidades e agentes formadores. Implodimos com mitos de origem que insistiam a nos tratar como membros de uma única cultura - primeiro a europeia e depois a nacional (única e fruto da miscigenação). De forma parecida, assumimos a necessária urgência de elaborarmos políticas e estratégias que combatam as desigualdades geradas por essências discriminatórias e que permitam aos diversos grupos ou componentes desse mosaico que é a Identidade Nacional (plural e diversa) se autoafirmarem, sendo valorizados e reconhecidos por todos.

Dessa forma, mesmo assumindo as limitações do uso dessa categoria, defendemos seu emprego em nossas análises e nos estudos escolares. Isso se deve ao fato de que ela permite não só refundar percepções identitárias, mas, principalmente, revelar que qualquer diálogo sobre o que devemos ensinar nas escolas deva passar pelas trajetórias históricas plurais e pelas diversas contribui- 
ções ao patrimônio cultural 'brasileiro' oriundas das mais diferentes sociedades, populações e agentes que participaram (ou participam) de sua formação.

\section{Os 'Entre-lugares’ da Identidade e da EducaÇÃo}

Ao analisar parte da obra ${ }^{6}$ do afro-martinicano Frantz Fanon, o teórico indo-britânico Homi Bhabha elaborou uma das mais reveladoras tentativas de explicar, interpretar e vivenciar o fenômeno da construção das identidades formadas pelas diásporas. As trajetórias desses dois indivíduos, forjadas elas mesmas pelas diásporas e pelos espaços criados em meio às relações coloniais e pós-coloniais, permitem que em suas expressões e apreensões de mundo encontremos claras aproximações com as realidades vividas por milhares de homens e mulheres que compartilharam histórias de vida correlatas. A sensação de pertencimento e estranhamento nas relações de identificação; a fabricação de culturas híbridas e as novas formas de inscrição cultural resultam do esforço de imaginar como tão complexas e diversas situações de contatos interculturais/multiculturais criaram o que Bhabha chamou de 'entre-lugares', ou seja, os processos de elaboração das novas identidades culturais.

O que é teoricamente inovador e politicamente crucial é a necessidade de passar além das narrativas de subjetividades originárias e iniciais e de focalizar aqueles momentos ou processos que são produzidos na articulação de diferenças culturais. Esses 'entre-lugares' fornecem o terreno para a elaboração de estratégias de subjetivação que dão início a novos signos de identidade...?

Homens 'hifenados' (afro-americano e indo-britânico), ambos os teóricos citados interpretam ou representam situações que podem espelhar os encontros e desencontros que acontecem nos espaços escolares dentro de sociedades multiculturais. Não podemos negligenciar o fato de que a Escola é um espaço marcado por discursos e práticas, tensões e debates. Os movimentos formativos e discursivos, a disciplinarização em conflito com a contestação e a educação formal esbarrando nas práticas pessoais são dinâmicas comuns nessas instituições. Representantes de uma percepção de mundo, de interesses dos agentes que operam o sistema educacional e de seus integrantes (docentes, estudantes, técnicos, família e sociedade), as Escolas devem ser pensadas como 
fronteiras, entendidas como Bhabha nos lembra: "lugar onde algo começa a se fazer presente" (2003, p.26-27).

Ou seja, apesar de apresentar conteúdos formais e preestabelecidos aos estudantes - prescritos por leis, normas e currículos -, a apropriação das 'lições', a construção de novas leituras de mundo e de entendimentos sobre as realidades coletivas e individuais apresentam-se justamente como parte de um movimento de elaboração de novas identidades. Identidades que não são aquelas apresentadas pelas abordagens do conteúdo preestabelecido ou as informadas pelos estudantes. Formas distintas de inscrição cultural se articulam nessa fronteira, tornando a Escola um espaço de grande relevância na formação de algumas de nossas múltiplas identidades.

O mais interessante é que na Escola ensina-se um tipo específico de memória, de História e de pertencimento. As experiências relativas à trajetória de vida pessoal de cada um de seus integrantes são inicialmente ignoradas. Seus sujeitos são vistos como subalternos a uma cultura e valores a serem apreendidos. Como em uma microesfera das experiências coloniais, a sala de aula torna-se um lugar de dominação cultural, de colonização imaginária. Nela uma suposta identidade comum ou pré-concebida (brasileiro, homem, mulher, negro, branco) desloca-se e conflita com uma alteridade complexa.

A imagem esperada do que definiria uma determinada entidade ('brasileiro') fragmenta-se e se torna insólita diante de tantos outros. Se, durante grande parte dos séculos XIX e XX, a escola reproduziu uma imagem homogênea de brasilidade - de franca ascendência europeia, branca, cristã, ocidental, masculina e elitista -, ao confrontar-se com outras expressões e inscrições culturais e identitárias - como a africanidade, a latinidade, as leituras feministas, as múltiplas filiações religiosas e não-elitistas - criou-se um espaço de conflito e recriação do que somos e de como nos percebemos e aceitamos.

Gusmão lembra que "a escola não consegue captar as expressões culturais presentes na modernidade e nas relações de identidade" servindo a determinados objetivos nas sociedades modernas: formar o cidadão e o profissional. Neste caso os debates sobre a memória cultural ou as diferentes formas de reconhecimento cultural estariam fora de suas intenções ou ações prioritárias, marcadas por claras distorções de origem. A única memória que deveria ser apreendida nas salas de aulas deveria ter base científica e se confundir com as ideias de nação e memória nacional, produzidas ou aceitas pelos agentes que 
defendem os discursos oficiais e homogeneizadores da Identidade Nacional (Gusmão, 2004, p.51-52).

Neste espaço, os saberes individuais, locais e das minorias seriam confrontados com o 'saber do professor' entendido como uma prática 'pedagógica que universaliza', como representante de um 'modelo único e uniforme de sociedade' que deveria ser ensinado e aprendido. Dessa forma a Escola se transforma em um espaço de rupturas com a realidade e com as experiências anteriores, no qual o diferente/heterogêneo deve ser igualado/homogeneizado. As múltiplas experiências pregressas acabam ignoradas e o entendimento de que a identidade só pode ser construída em um fluxo constante na relação com a alteridade parece não ser reconhecido (Gusmão, 2004, p.51-54).

Um dos caminhos teóricos possíveis para o entendimento e para a resolução dos problemas gerados por essa percepção de identidade pela Escola poderia ser exemplificado pelas novas realidades geracionais e perfis identitários de alguns países europeus no período pós-colonial. Tocados por um processo intenso de imigração originária dos países africanos e asiáticos (percebidos como ex-colônias), as sociedades europeias - como em Portugal, Inglaterra e França - se viram forçadas a redefinir suas fronteiras identitárias, já que o $\mathrm{Ou}$ tro, agora, não se encontrava mais no espaço do 'além-mar'. O Outro, agora, ocupava espaços próximos demais, como as ruas, os centros comerciais, as escolas, as áreas de lazer e os locais de trabalho das próprias cidades europeias. Mais do que isso, esse Outro - 'africano', 'negro', 'muçulmano', 'colonizado' - se identificava como igual, pelo menos na atribuição de uma Identidade Nacional em comum, ou na reivindicação de igualdades jurídica, econômica e social, quando se tratava das gerações descendentes dos primeiros imigrantes, que chegaram em larga escala à Europa nas décadas de 1950, 1960 e 1970.

Guardadas as devidas proporções e reconhecidas as diferenças entre os contextos, o quadro vivenciado em alguns desses países no período colonial e pós-colonial nos incentiva a construir referências sobre como empregar o conceito de 'identidade'. No caso daqueles países pelo encontro desconcertante do $\mathrm{Eu}$ (europeu, branco, ex-colonizador) e do Outro (africano, negro, ex-colonizado) no tempo presente. Identidade e Alteridade se apresentam em pleno potencial de conflitos e tensões. No caso brasileiro, a situação ganha um novo fator: a 'aliedade', que alguns teóricos definem como a alteridade experimentada no tempo, o encontro do Eu (no presente) com o Outro (deslocado no 
tempo, para o passado), que ocorre em uma combinação imaginária (Gusmão, 2004, p.55-57).

Em uma das faces de nosso mosaico identitário, as relações ocorrem entre o 'brasileiro' de hoje e o 'africano' de ontem, que se encontram no presente. É certo que, de alguma forma, essa relação diacrônica dialoga com outras faces de nossas identidades, como aquelas estabelecidas pelas dinâmicas relacionais que se encontram submersas no passado e deitam raízes no presente, quando o antigo $\mathrm{Eu}$ (branco, senhor) se relaciona com o antigo Outro (negro, escravo). Obviamente, por fim, não podemos esquecer as relações que ocorrem no hoje, entre brancos (eurodescendentes) e negros (afrodescendentes), 'brasileiros' que compartilham um processo de identificação complexo. Portanto, essas relações aparecem tingidas pelas questões raciais do hoje e do ontem.

Para entendermos melhor como empregar as referências teóricas sobre a Identidade em nosso cotidiano escolar sintetizei a seguir as reflexões de Bhabha e Fanon acerca do tema, dividindo-as em três modelos. Eles serviriam para que professores e estudantes compreendessem de forma mais panorâmica a importância dos debates acerca das relações étnico-raciais em nossas salas de aulas e no estudo da História da África.

No modelo 1, que denominamos de 'binário', há uma relação marcada pelo franco antagonismo. É na verdade uma relação de absoluta negação e de não reconhecimento. Como forças da 'física' que se repelem, que não se comunicam, o Eu e o Outro são definidos de forma essencialista, autônoma. Como se, em uma inexplicável inversão, a identidade e a alteridade se rejeitassem plenamente para existir. Esse modelo, mais matemático do que antropológico, cria um obstáculo e não uma ponte entre essas duas entidades. Um tipo de vidro que permite que ambos se vejam, mas não se aproximem, que se estranhem, mas não se misturem, como em um falso jogo de espelhos.

No modelo 2, que denominamos de 'as identidades colonizadas', existiriam algumas condições subjacentes para a compreensão do 'processo de identificação’. Lembramos que esse processo seria vivido nas relações estabelecidas entre os indivíduos que se encontravam na condição de 'colonizado' e de 'colonizador', de 'africano' e de 'europeu', de 'negro' e de 'branco'. Segundo Fanon, tal situação relacional, marcada por um fluxo invertido de 'demandas' e 'desejos', estaria condicionada ou seria cunhada em uma moeda única de dupla face, com duas imagens que projetariam duas identidades antagônicas, mas dependentes. 
O Eu (branco, europeu, colonizador) desejando preservar sua condição de dominador, cuja demanda só existia pela presença e pela situação do Outro (negro, africano, colonizado). E o Outro desejando ocupar o lugar do Eu, condição demandada pela sua situação de subjugado. Fanon afirmava que tal condição poderia ser sintetizada da seguinte forma: "O preto escravizado por sua inferioridade, o branco escravizado por sua superioridade, ambos de acordo com uma orientação neurótica ... o que é frequentemente chamado de alma negra é um artefato do homem branco" (Fanon, apud Bhabha, 2003, p.74-75).

Por fim, há o esquema que acreditamos ser o mais explicativo para o nosso caso. No modelo 3, que chamaremos de 'identidades híbridas', nos apoiamos nas interpretações de Homi Bhabha sobre as relações de identidade. Nesta operação "o lugar do outro não deve ser representado ... como um ponto fenomenológico fixo oposto ao eu". Sua definição seria mais complexa e norteadora da realidade de uma sociedade multicultural, já que o "outro deve ser visto como a negação necessária de uma identidade primordial - cultural ou psíquica” -, como é, por exemplo, a falsa ideia de UMA identidade nacional, definida por UMA cultura nacional, ou por UMA única ideia de pertencimento. Dessa forma o Outro "introduz o sistema de diferenciação que permite ao cultural ser significado como realidade linguística, simbólica, histórica". Mais do que isso, "como princípio de identificação, o outro outorga uma medida de objetividade, mas sua representação é sempre ambivalente", ou seja, ele é composto por princípios conflitantes, retirados das substâncias formativas do Eu e do Outro. "A identificação é sempre uma questão de interpretação, pois ela é um encontro furtivo entre mim e um si-próprio, a elisão da pessoa e do lugar" (Bhabha, 2003, p.86-87).

O que parece ser diferenciado nesse modelo é que ele introduz uma nova dimensão de representação na relação entre o Eu e o Outro. Se antes a observação fixava-se nas imagens que refletiam nos espelhos vítreos que serviam como fronteira nessa relação, agora, seria preciso acrescentar uma perspectiva de profundidade e substituir o espelho ou janela por uma fronteira articular, que funde, ao invés de separar. Essa representação permite construir um esquema no qual uma forma híbrida, em movimento, substitui a forma binária (da soma ou da subtração) no esforço de decifrar as dinâmicas da construção da identidade e da alteridade. Sendo assim, as inscrições de pertencimento dos indivíduos são forjadas não mais no duelo de imagens, da rejeição ou na adesão a certas características. Tanto o eu como o outro não passam de projeções 
que se articulam no fenômeno da identificação quando suas sombras se encontram no espaço relacional, ou no intervalo (o entre-lugar) criado pelas fronteiras, ou seja, no espaço onde se fabrica uma identidade da alteridade ou uma alteridade da identidade.

À medida que uma série de grupos cultural e racialmente marginalizados assume prontamente a máscara do negro, ou a posição da minoria, não para negar sua diversidade, mas para, com audácia, anunciar o importante artifício da identidade cultural e de sua diferença, a obra de Fanon torna-se imprescindível. À medida que grupos políticos de origens diversas se recusam a homogeneizar sua opressão, mas fazem dela causa comum, uma imagem pública da identidade da alteridade, a obra de Fanon torna-se imprescindível - imprescindível para nos lembrar daquele embate crucial entre máscara e identidade, imagem e identificação, do qual vem a tensão duradoura de nossa liberdade e a impressão duradoura de nós mesmos como outros. (Bhabha, 2003, p.102)

Para além da conhecida tese das zonas ou áreas de contato interétnico e intercultural - espaços nos quais semelhanças e diferenças são postas à prova -, a perspectiva de se pensar as fronteiras identitárias e culturais como os 'entre-lugares' que informam os "momentos ou processos que são produzidos na articulação de diferenças culturais" torna o modelo 3 mais adequado ao nosso debate. De forma clara ele revela que não existem identidades essenciais, puras ou absolutas. As identidades não passam de representações ou projeções do que acreditamos ser, do que acreditamos ser o Outro, e do que esse Outro acredita que sejamos. Nesse jogo de projeções, o processo de identificação só pode ocorrer justamente na fronteira (entendida como espaço relacional ou como o 'lugar onde algo começa a se fazer presente') entre essas projeções. Imagens, representações e projeções de identidades se encontram nesse espaço relacional, e é nele que as identidades serão construídas.

No caso brasileiro torna-se evidente que a elipse poderia ser pensada como a representação dos 'processos de identificação' que envolvem obviamente a própria Identidade Nacional. No entanto, isoladamente, ela - a Identidade Nacional - não representa nada, não se sustenta. São seus componentes, os Mesmos e os Outros, que em seus movimentos projetam suas sombras identitárias para o centro da fronteira relacional, permitindo tanto o reconhecimento dessas múltiplas identidades, a revelação das pluralidades culturais como 
também um entendimento mais adequado do significado da Identidade $\mathrm{Na}$ cional. Portanto, essas múltiplas identidades não são excludentes e não estão isoladas. Elas são relacionais e, na relação com o todo, complementares.

Neste caso devemos frisar que não existe, ou não deveria existir uma hierarquia entre essas identidades. Afro-brasileiros, luso-brasileiros, ítalo-brasileiros, nipo-brasileiros, teuto-brasileiros, sociedades indígenas e aqueles que não se identificam pelas representações 'hifenadas', portanto, apenas 'brasileiros', além de todos os seus descendentes, compõem o mosaico identitário que poderíamos chamar de Identidade Nacional. Complexa, diversa, heterogênea, plural. Justamente quando uma condição de desigualdade é criada entre esses grupos ou categorias de identificação - e este parece ser o caso de várias sociedades contemporâneas -, torna-se necessária a intervenção da sociedade civil, das instituições, dos movimentos sociais e do Estado para equacionar as tensões e distorções criadas.

Como articular ou aproximar essa discussão toda de nossas experiências ou cotidianos nas salas de aula? Essa é uma das demandas da Educação das Relações Étnico-raciais. Ao partirmos da constatação de que as escolas, no sistema educacional contemporâneo, desempenham papel relevante na construção de percepções de mundo e na divulgação de informações e conteúdos, que deveriam compor aquilo que chamamos de 'memórias compartilhadas', parece inquestionável a necessidade de ampliarmos nossos recortes temáticos, conteúdos programáticos e abordagens reflexivas nas salas de aulas.

Herdeiros de uma escola que privilegiou, em grande parte de sua trajetória, conteúdos eurocêntricos, vivemos hoje a urgência de rever conteúdos e temas formativos em nossos bancos escolares. Se adotarmos o paradigma identitário anteriormente apresentado - o das Identidades e Culturas Plurais que compõem a Identidade Nacional -, torna-se óbvio o fato de que no trabalho com História, Geografia, Artes, Literatura, Filosofia e Música não podemos valorizar, ensinar e aprender padrões de conhecimento relativos a apenas uma matriz formativa, no caso a europeia. Precisamos conhecer, reconhecer, valorizar e respeitar as outras matrizes que participaram dessa formação - por exemplo, as africanas, as asiáticas e as indígenas.

A questão é, de fato, relacional. É preciso estarmos convencidos da relevância de debater a questão das identidades nas escolas para que possamos convencer nossos alunos sobre seu papel formativo e funcional em nosso cotidiano. Mais 
do que isso, ao redefinirmos nossos princípios de identidade, torna-se insustentável a manutenção da matriz curricular que grande parte das escolas reproduzia até o início deste século. É certo que importantes mudanças começaram a ocorrer no campo legal ou prescritivo vinculados à educação a partir da última década do século XX, resultados de demandas de movimentos sociais e do convencimento por parte dos intelectuais e políticos de que o debate sobre as nossas múltiplas identidades e a Identidade Nacional deveria ser reinaugurado.

Naqueles anos, tornou-se consensual que não mais poderíamos pensar a sociedade brasileira como portadora de um único signo identitário, como portadora de um único padrão cultural. O multiculturalismo entrava em cena oficialmente na LDB de 1996, nos PCNs, produzidos nos anos seguintes, e na promulgação das Leis federais 10.639/03 e 11.645/08, além das Diretrizes Curriculares Nacionais relacionadas ao ensino de História da África e à Educação Étnico-Racial. Desde então, para além das matrizes europeias, as outras matrizes de formação de nossa sociedade - entre elas as africanas - deveriam obrigatoriamente aparecer nos currículos, livros didáticos, cursos de formação de professores e, por fim, nas salas de aula.

\section{REFLEXÕES FINAIS}

Chegamos ao ponto. Ensinar, aprender, refletir e debater sobre as 'identidades' é um exercício fundamental para o combate à intolerância, à discriminação, à xenofobia, ao racismo e ao sexismo. É uma ferramenta obrigatória no esforço de construir uma sociedade mais justa e, efetivamente, plural. $\mathrm{O}$ respeito ao Outro, seja ele quem for, tornar-se-ia ato rotineiro. Essa é uma das obrigatórias articulações que devemos fazer.

Em complemento a esse primeiro ponto, outro se torna correlato. Princípios como do autorreconhecimento, da alta autoestima identitária, do reconhecimento pelo Outro, do respeito e da valorização das diferentes sociedades e culturas só se tornam possíveis com os aprendizados/conhecimentos que temos sobre essas sociedades e culturas. Competindo com a comunicação social, a televisão, a internet e o cinema, a Escola transforma-se em um espaço também de fabricação de imaginários e de conhecimentos sobre o Eu e os Outros. Portanto, o estudo da história e das culturas africanas não é importante apenas para aqueles que se identificam como membros dessa identidade, 
mas para TODOS. Valorizar e respeitar são importantes práticas que devemos trabalhar em nossas salas de aulas. Conhecer as contribuições para a construção do patrimônio histórico-cultural da humanidade e do Brasil dessas sociedades permite que tenhamos uma visão mais panorâmica da nossa condição humana, de nossas múltiplas identidades e de nossa pluralidade cultural.

\section{NOTAS}

${ }^{1}$ Uma versão anterior e modificada deste texto foi apresentada como parte introdutória de material instrucional a ser utilizado no curso de Aperfeiçoamento de Docentes promovido pelo Centro Integrado de Aprendizagem em Rede (Ciar), da Faculdade de História da Universidade Federal de Goiás.

${ }^{2}$ Entre algumas das principais referências podemos citar os seguintes trabalhos: APPIAH, Kwame Anthony. Na casa de meu pai. Trad. Vera Ribeiro. 1.ed. Rio de Janeiro: Contraponto, 1997; APPIAH, Kwane Anthony. La ética de la identidad. Trad. Lilia Mosconi. 1.ed. Buenos Aires: Katz, 2007; BHABHA, Homi. Race time and the revision of modernity. In: BACK, Les; SOLOMOS, John (Org.) Theories of race and racism. London: Routledge, 2000. p.354-368; GILROY, Paul. Entre campos: nações, culturas e o Fascínio da Raça. São Paulo: Annablume, 2007; GILROY, Paul. O Atlântico Negro: modernidade e dupla consciência. Rio de Janeiro: Ucam; Ed. 34, 2001; HALL, Stuart. Da diáspora: identidades e mediações culturais. Belo Horizonte: Ed. UFMG, 2009; HALL, Stuart. Old and new identities, old and new ethnicities. In: BACK; SOLOMOS (Org.), 2000, p.144-153;

MBEMBE, Achille. As formas africanas de autoinscrição. Revista Estudos Afro-Asiáticos, Rio de Janeiro, ano 23, n.1, p.171-209, 2001.

${ }^{3}$ Ver BRASIL. Ministério da Educação. Secretaria de Educação Fundamental. Parâmetros Curriculares Nacionais. Terceiro e quarto ciclos do ensino fundamental: introdução aos parâmetros curriculares nacionais. Brasília: MEC/SEF, 1998 (a), p.55.

${ }^{4}$ Como é de conhecimento geral, a LDB, no que diz respeito ao ensino de história africana, foi alterada pelas Leis $n^{\circ} 10.639$, de 9 jan. 2003, e 11.645, de 10 mar. 2008. O trecho citado encontra-se no $4^{\circ}$ parágrafo do artigo 25.

${ }^{5}$ GUSMÃO, Neusa Maria Mendes de. Os filhos da África em Portugal: antropologia, multiculturalidade e educação. Lisboa: Imprensa de Ciências Sociais, 2004. p.61.

${ }^{6}$ Principalmente as seguintes referências: FANON, Frantz. Pele negra, máscaras brancas. Rio de Janeiro: Fator, 1983; FANON, Frantz. Os condenados da Terra. Rio de Janeiro: Civilização Brasileira, 1979.

${ }^{7}$ BHABHA, Homi. O local da cultura. Belo Horizonte: Ed. UFMG, 2003. p.20.

Artigo recebido em 20 de janeiro de 2012. Aprovado em 26 de março de 2012. 